\title{
Determination of Background Ionizing Radiations in Selected Buildings in Nairobi County, Kenya
}

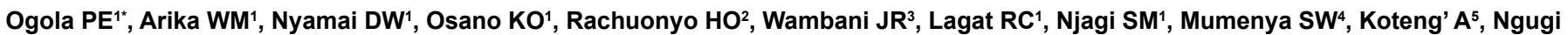 \\ MP $^{1}$ and Oduor RO'
}

${ }^{1}$ Department of Biochemistry and Biotechnology, School of Pure and Applied Sciences, Kenyatta University, P.O. Box 43844-00100, Nairobi, Kenya ${ }^{2}$ Department of Microbiology, School of Pure and Applied Sciences, Kenyatta University, P.O Box 43844-00100, Nairobi, Kenya

${ }^{3}$ Department of Medical Laboratory Sciences, School of Medicine, Kenyatta University, P.O Box 43844-00100, Nairobi, Kenya

${ }^{4}$ University of Nairobi, P.O. Box 19320-00202, Nairobi, Kenya

${ }^{5}$ Radiation Protection Board, P.O. Box 19841-00202, Nairobi, Kenya

\begin{abstract}
A survey taken by the world health organization $(\mathrm{WHO})$ and the international commission on radiation protection (ICRP) shows that certain materials used for the construction of such buildings (rocks soils) are known to be radioactive. Exposure to indoor ionizing radiation like exposure to any other type of ionizing radiation results in critical health challenges. This work set out to determine the levels of background ionizing radiations in selected buildings around Nairobi County and its environs. The Radiation Alert R (Digilert 200) meters were used to capture the readings. The meters were held about $1 \mathrm{~m}$ above ground level and readings were recorded in $\mathrm{mR} / \mathrm{h}$ for all buildings. Numerical data was subjected to analysis of variance using Minitab version 17.0 to determine the statistical differences of exposure levels within various areas. A total of 400 buildings were sampled. The annual indoor readings were highest in Eastleigh $(4.070 \mathrm{mSv})$ and relatively lowest in Nairobi Central Business District (CBD) at $2.763 \mathrm{mSv}$, representing a deviation from WHO recommended standard of $307.0 \%$ and $176.3 \%$, respectively. None of the buildings sampled had exposure levels below the WHO recommended standard of $1 \mathrm{mSv}$. Overall, these results indicate presence of higher levels of ionizing radiations in buildings beyond the acceptable annual threshold thereby posing significant health risk to the public. Consequently, these results could find great application in guiding the formulation of the national building code to include routine surveillance of the background ionizing radiation levels in various buildings to assess the health risk of general public as well as exploring appropriate mitigation approaches.
\end{abstract}

Keywords: Cancer; Radiation; Mutation; Premises

\section{Introduction}

Radiation has been found to be beneficial on one hand and harmful on the other hand and is encountered in everyday activities in various forms and different intensities. Some of the harmful effects are: cancer, cataract, gene mutation destruction of bones and blood cells and it can cause the death of an individual [1]. These radiations come from three main sources namely: cosmic radiation, terrestrial radiation and radioactivity in the human body [2]. In Kenya, indoor background ionizing radiation has received no attention, even though studies have established the presence of dangerous background ionizing radiation within buildings. Indoor background ionizing radiation investigation is important because some of the materials used in the construction of buildings are known to be radioactive [3]. It has been established that chronic exposure to even low dose rate of nuclear radiations from an irradiated building has the potential to induce cytogenetic damage in human beings [4]. Of particular concern is that such background ionizing radiations occur naturally from the sun, in rocks and soil and can cause changes in human cell including genetic mutation thus leading to cancer. Majority of the buildings in Kenya are usually constructed using stones and sand mined from underground rocks and river beds yet they have not been adequately radio-profiled to determine the levels of embedded radio-nuclides capable of emitting ionizing radiations. Conventionally, the World Health Organization (WHO) recommends that the annual exposure to the ionizing radiation to the general public should not exceed $1 \mathrm{mSv}$.

\section{Materials and Methods}

\section{Study area}

The study area involved various quarry sites located around Nairobi
County (Figure 1). Nairobi was selected because it is the capital city of Kenya and is surrounded by several expanding suburbs. The city is governed by the County Government of Nairobi. The city lies on the Nairobi River in the southern part of country, and has an elevation of 1,795 metres $(5,889 \mathrm{ft})$ above sea level. Nairobi is the 14th-largest city in Africa, including the population of its suburbs. Nairobi County was founded in 2013 on the same boundaries as Nairobi Province. According to 2009 census, the city of Nairobi $\left(1^{\circ} 17^{\prime} \mathrm{S} 36^{\circ} 49^{\prime} \mathrm{E}\right)$ has an estimated population of about 3.13 million people. In addition, Nairobi's industrial activities have been acknowledged as the basis of modern development due to their important contribution to the economic growth and wellbeing of its inhabitants and general citizenry.

\section{Study design}

Nairobi was divided randomly into eight sampling estates. These estates included Kasarani, Buruburu, Kahawa, Kinoo, CBD, Mlolongo, Eastleigh and Ruaka. The indoor radiation levels of 400 units were measured. The measurements were captured with the radiation meter held away from sampled surfaces in all the areas. In every premise/unit,

*Corresponding author: Ogola Phillip Einstein, Department of Biochemistry and Biotechnology Kenyatta University, P.O. Box 43844-00100, Nairobi, Kenya, Tel: +254723916063; E-mail: phileinst@gmail.com

Received April 07, 2016; Accepted May 24, 2016; Published May 31, 2016

Citation: Ogola PE, Arika WM, Nyamai DW, Osano KO, Rachuonyo HO, et al. (2016) Determination of Background lonizing Radiations in Selected Buildings in Nairobi County, Kenya. J Nucl Med Radiat Ther 7: 289. doi:10.4172/21559619.1000289

Copyright: ( 2016 Ogola PE, et al. This is an open-access article distributed under the terms of the Creative Commons Attribution License, which permits unrestricted use, distribution, and reproduction in any medium, provided the original author and source are credited. 


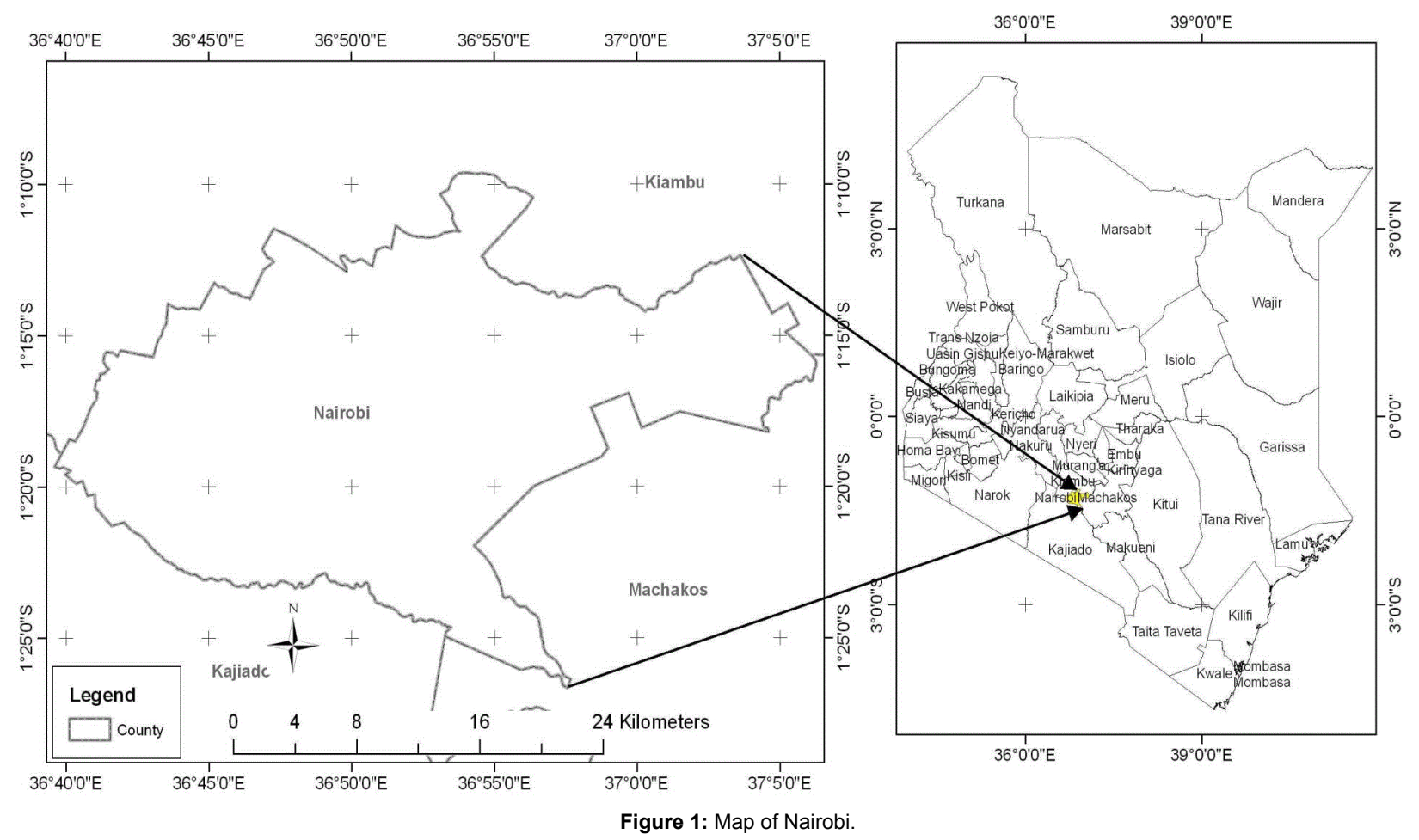

eight indoor measurements were recorded. A total of four readings were recorded for each unit. Global Positioning System (GPS) was used to measure the precise location of sampling. Analysis of spatial distribution of data was performed using ArcGIS software version 10

\section{Determination of Radiation Levels in Premises}

Measurements of indoor radiation were taken in eight different points per premise and the same procedure repeated in other premises. The readings were captured in milli Roentgew per hour $(\mathrm{mR} / \mathrm{h})$. At each point, samples of four measurements were taken and the mean value calculated.

\section{Data Management and Statistical Analysis}

The readings were then recorded in a work sheet and entered in Microsoft excel spreadsheet for analysis. UNSCEAR in 1988 recommends an indoor occupancy factor of 0.8 . The occupancy

factor $(\mathrm{OF})$ represents the proportion of the total time during which an individual is exposed to radiation field. The readings were converted from hours to years under the assumption that humans live in their premises for $24 \mathrm{~h}$ a day. When converting the indoor readings to annual equivalent doses in $\mathrm{mSv} / \mathrm{y}$ for the premises, the following equation was used.

\section{$\mathrm{E} 1=\mathrm{X} \times 8760 \times 0.8 \times 0.01 \times 1.7$}

$\mathrm{E} 1$ is the annual equivalent dose rate in $\mathrm{mSv} / \mathrm{y}$.

$\mathrm{X}$ is the indoor meter reading in $\mathrm{mR} / \mathrm{h}$.

8760 is the annual conversion factor in hours/year.

0.8 is the indoor occupancy factor

0.01 is the conversion of $\mathrm{mR}$ to $\mathrm{mSv}$

\section{7 is the calibration factor.}

The data was subjected to descriptive statistics and were expressed as Means \pm SEM. One way ANOVA was used to test the significance within the premise clusters at $95 \%$ confidence level. The data was further subjected to Turkey's post hoc for pairwise comparison and separation of means. Minitab version 17.0 was used to determine the significant relationships between the radiations from different premises. The findings were presented through tables that showed levels of mean radiation levels between the various premises and their differences in statistical significance. The results were further computed relative to the recommended WHO annual dose reference of $1 \mathrm{mSv}$. The percentage deviations were calculated by getting the percentage of the difference of the annual reading from the $\mathrm{WHO}$ standard. The results were presented in tables and spatial distribution of data was presented in maps.

\section{Results}

A total of eight randomly selected estates were sampled for this study (Figure 2). In all the 400 units sampled, none of the premises had ionizing radiations below the recommended annual standard of 1 $\mathrm{mSv}$. In Mlolongo, 40 units were sampled (Figure 3). None of the 40 premises had readings below the recommended threshold (Table 1). It was observed that $58 \%$ of the units fell between the clusters of $101 \%$ $200 \%$ followed by $25 \%$, which fell in the cluster of $201 \%-300 \%$. In CBD, 100 premises were sampled (Figure 4 and Table 1). A similar trend was observed whereby $67 \%$ of the sampled units fell in the clusters of $101 \%$ $200 \%$ while $21 \%$ of the units were in the clusters of $201 \%-300 \%$ (Table 1). In eastern side of Nairobi, a total of 50 units were sampled in Kasarani (Figure 5; Table 1). A high number of units $48 \%$ was observed in $201 \%$ $300 \%$ followed by $30 \%$ in the clusters of $101 \%-200 \%$. In Eastleigh, out of the 60 units sampled, $38 \%$ of them fell in the clusters of $301 \%-400 \%$ followed by $34 \%$ that was in $201 \%-300 \%$ clusters (Figure 6; Table 1). In Ruaka (Figure 7), Kinoo (Figures 6-8) and Buruburu (Figure 9), 31, 29 


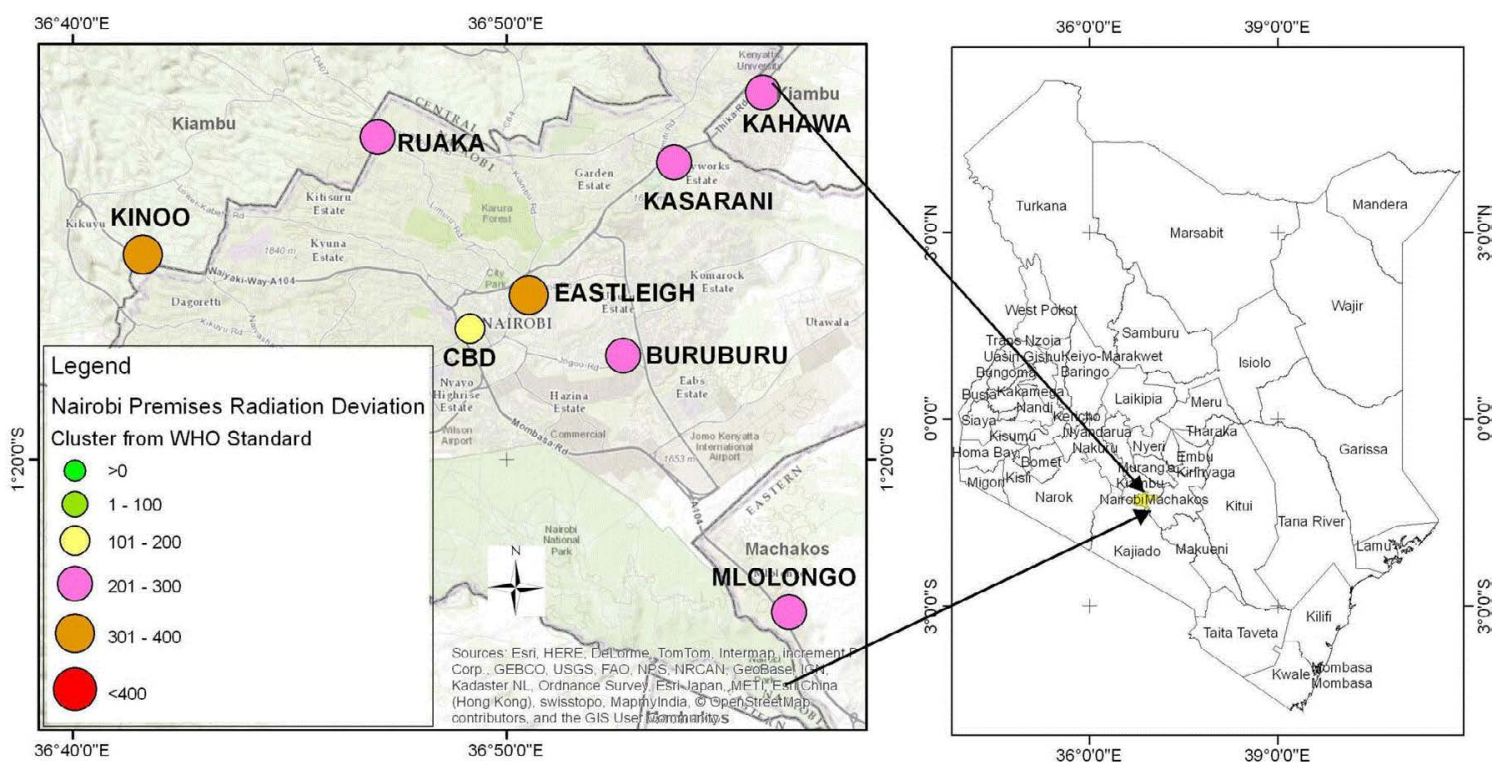

Figure 2: Distribution of indoor ionizing radiation data from 8 different estates in Nairobi County and its environs.

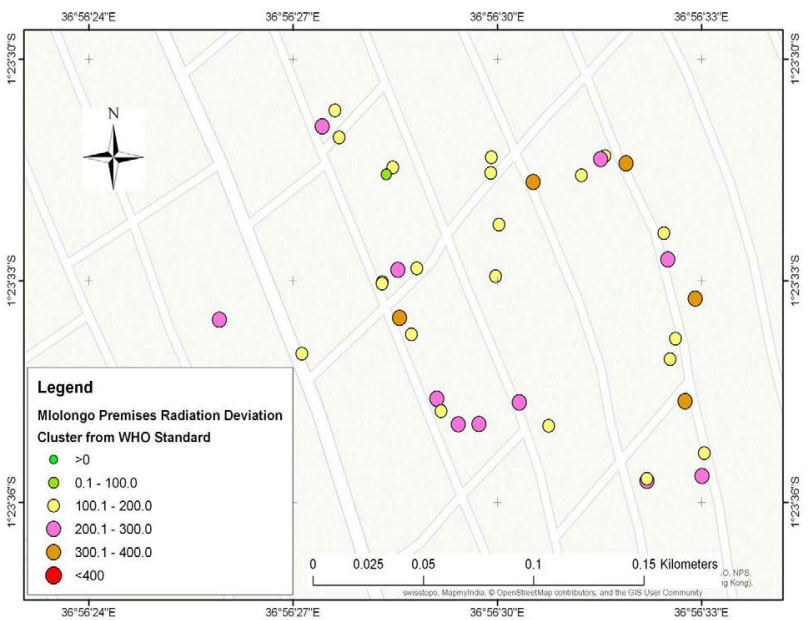

Figure 3: Percentage annual deviation from WHO recommended exposure standard of ionizing radiation in Mlolongo.

and 59 units were sampled, respectively. A high number of premises were captured in the cluster of $201 \%-300 \%$ in the three estates with Ruaka having 55\%, Kinoo $45 \%$ and Buruburu $47 \%$. In the clusters of $101 \%-200 \%, 7 \%$ of the premise units was observed in both Ruaka and Kinoo. Kahawa estate (Figure 10) had 31 premises sampled out of which $45 \%$ fell in the $301 \%-400 \%$ followed by $36 \%$ in $201 \%-300 \%$ and $19 \%$ in $101 \%-200 \%$ (Table 1 ).

A summary of the percentage annual deviation from WHO recommended standard of ionizing radiation in Nairobi County and its environs showed that majority of the premises (36\%) were in the deviation cluster of $201 \%-300 \%$ while $2 \%$ were in $1 \%-100 \%$ deviation cluster (Table 2). None of the premises sampled had their deviation cluster below the acceptable threshold. In addition, $5 \%$ of the premises had their annual deviations above $400 \%, 24 \%$ were in the cluster of $301 \%-400 \%$ and $33 \%$ were between $101 \%-200 \%$ (Table 2). From the annual exposure to ionizing radiation in premises around Nairobi County and its environs it was observed that Ruaka, Kinoo and

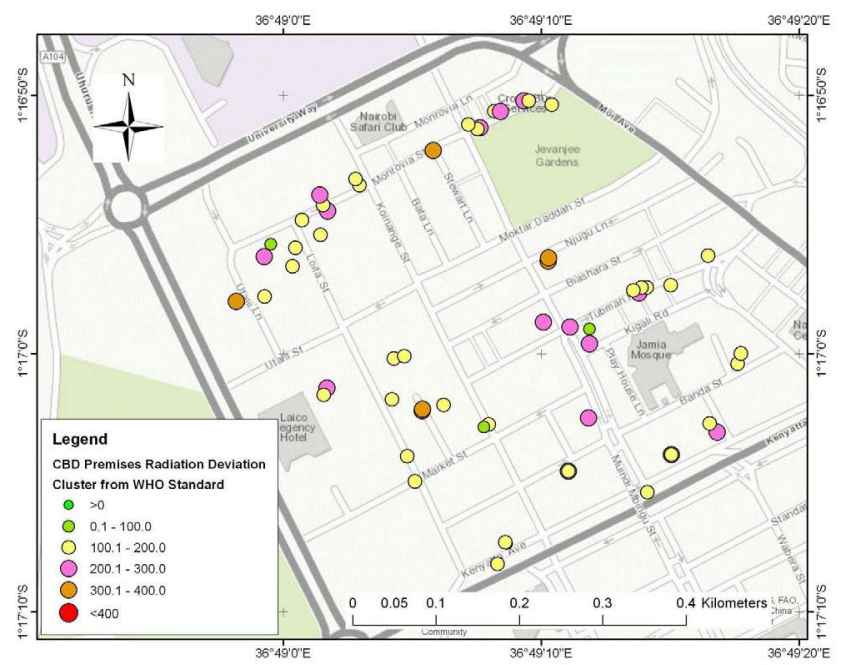

Figure 4: Percentage annual deviation from $\mathrm{WHO}$ recommended exposure standard of ionizing radiation in CBD.

Eastleigh showed ionizing radiation levels that were not significantly different from each other ( $p>0.05$; Table 3$)$. In addition, Kahawa and Buruburu were not significantly different from each other, $(p>0.05)$ while Kasarani, Mlolongo and CBD had ionizing radiation levels that were significantly different from each other $(p<0.05)$. Eastleigh had the largest deviation from WHO with $307 \%$ while CBD had the lowest deviation with $176.3 \%$ (Table 3 ).

\section{Discussion}

The results of this study show that none of the estates sampled had annual indoor exposure levels below the acceptable standards set by WHO. It was observed that the readings varied between the estates. Eastleigh, Kinoo and Ruaka were not statistically significant from each other. In addition, Buruburu and Kahawa were also not significantly different. CBD, Kasarani and Mlolongo were significantly different. 


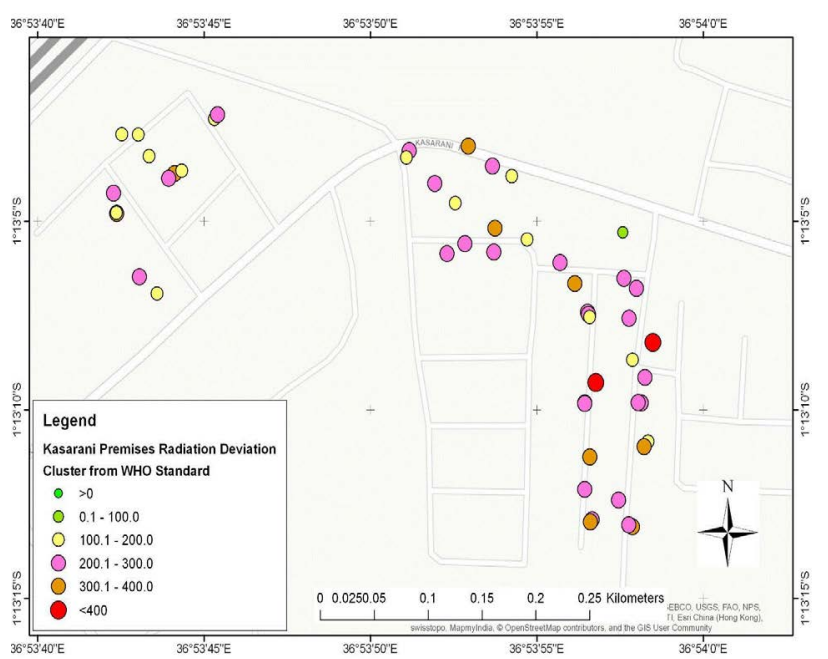

Figure 5: Percentage annual deviation from WHO recommended exposure standard of ionizing radiation in Kasarani.

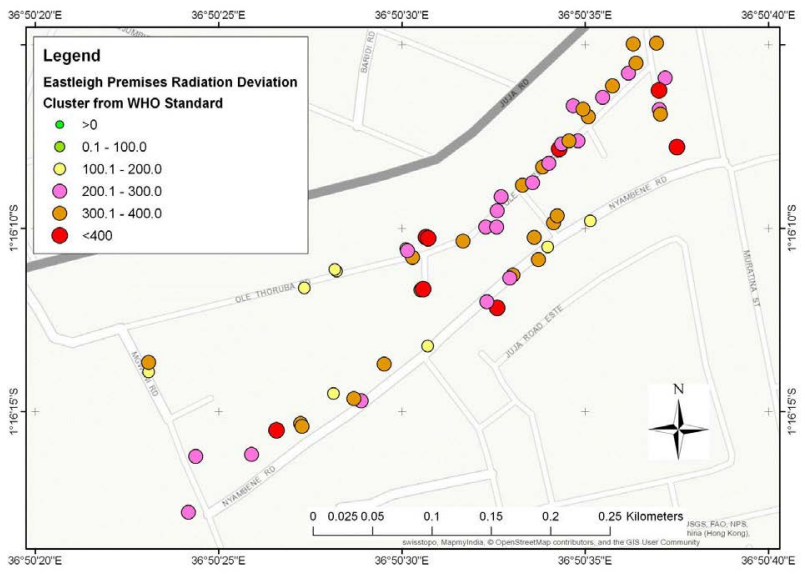

Figure 6: Percentage annual deviation from WHO recommended exposure standard of ionizing radiation in Eastleigh.

High levels of indoor radiation might be attributed to the rocks used for the construction of the buildings were mostly igneous rocks which are believed to be rich in minerals like zircon, monazite, uranite, potassium, feldspars and biotite [5,6]. The annual mean indoor levels of exposure was high in Eastleigh with a reading of $4.070 \mathrm{mSv}$ while Nairobi CBD had the lowest annual mean indoor reading of $2.763 \mathrm{mSv}$. These values are, however, above the $1.0 \mathrm{mSv}$ acceptable limits for public exposure. Kahawa and Kasarani had high readings of $3.713 \mathrm{mSv}$ and $3.407 \mathrm{mSv}$ respectively. Therefore, the inhabitants are exposed to high levels of ionizing radiation. A study in 2014 revealed that any exposure to ionizing radiation has the tendency to change the biological make-up of the human body which may result in radiation induced sicknesses [7]. Furthermore, the high radiation values may also be due to the sand and soil used for the building construction that might contain traces of Uranium and Thorium which contribute to background radiation $[7,8]$. Moreover, this may imply that the building stones used for the foundation of the buildings originated from mostly igneous rocks which are believed to be rich in minerals like Zircon, Monazite, Uranite, Potassium, Feldspars and Biotite [9]

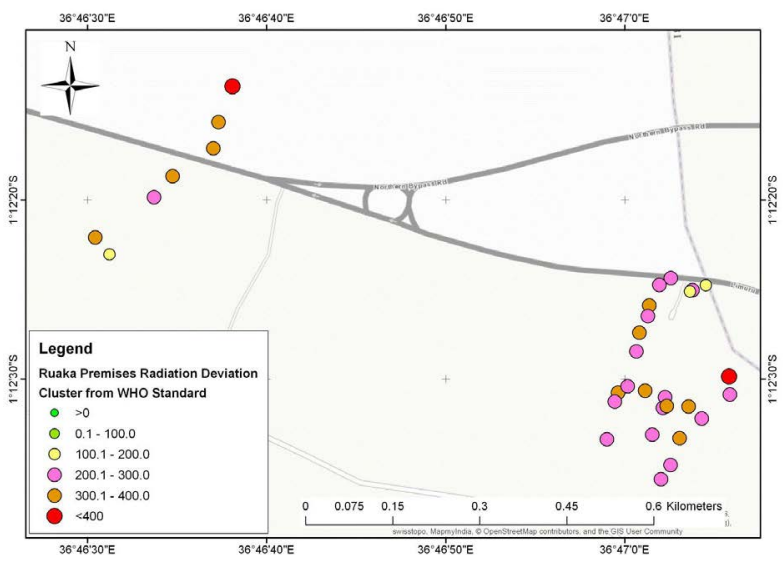

Figure 7: Percentage annual deviation from WHO recommended exposure standard of ionizing radiation in Ruaka.

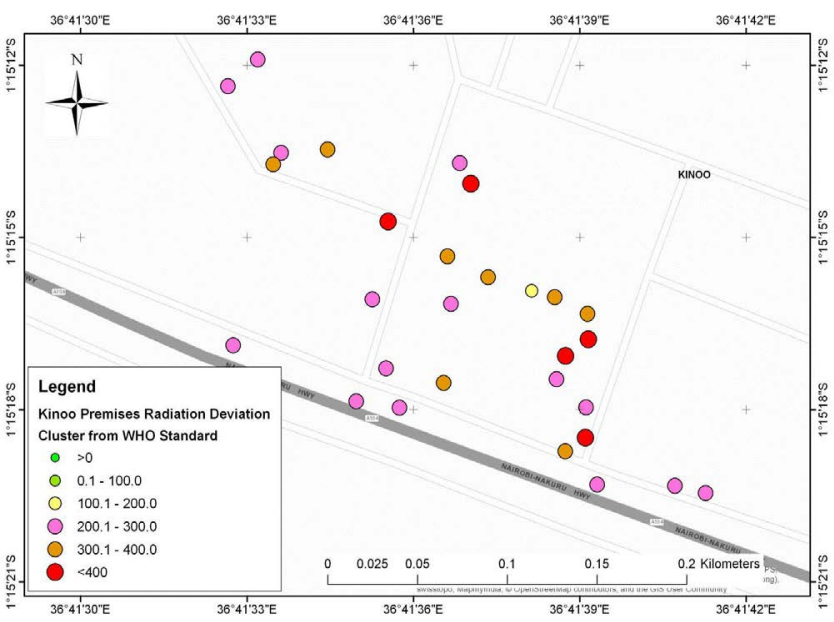

Figure 8: Percentage annual deviation from WHO recommended exposure standard of ionizing radiation in Kinoo.

which release ionizing radiation. Furthermore, elevated radiation levels may be due to the way some of the buildings were constructed as part of the roof is made up of concrete. The results of this study are in agreement with a study carried out in 2015 whereby an assessment of indoor background radiation levels in Plateau State University, Nigeria showed that the mean indoor annual equivalent dose rates were high [10]. The results obtained were higher than those obtained in a study carried out in 2014, which recorded an equivalent dose of $2 \mu \mathrm{Sv}$ per scan $(0.73 \mathrm{mSv})$ received by people in those surroundings during an $\mathrm{X}$-ray scanning of a container [11]. This value is really small compared to mean of indoor annual effective dose of $4.07 \mathrm{mSv}$ that was obtained in this work in Eastleigh. This discrepancy may be due to compliance with safety procedures by the personnel. In addition, the results are higher compared with previous work at radio diagnostic center, Plateau State specialist hospital [8] and Braithwaite Memorial Specialist Hospital Port Harcourt, Rivers State [12]. Since the mean effective dose equivalent in all the areas is higher than the $1.0 \mathrm{mSv}$ annual effective dose for general public in the study area, long term exposure of the public to these radiations may lead to radiation induced health hazard such as erythema, skin cancer, genetic mutation and sterility [13]. Some of the places that receive high levels of background natural radiations in the world include Kerala in India, Ramsar in Iran and Guarapari in 


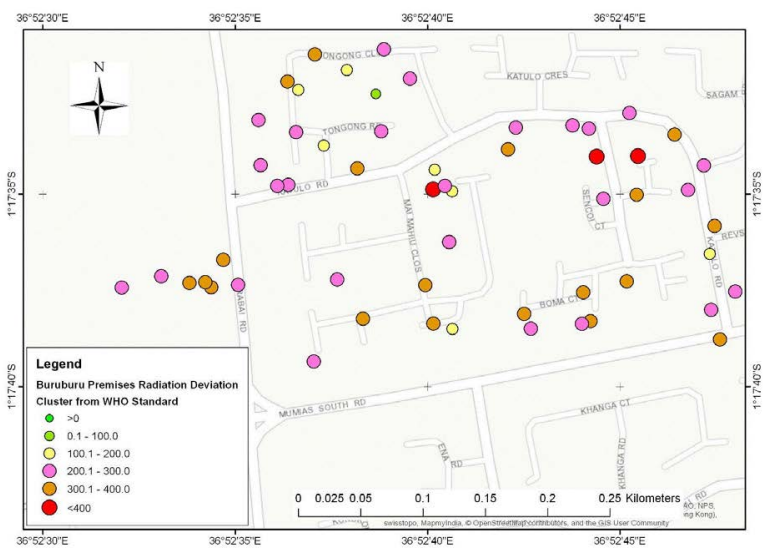

Figure 9: Percentage annual deviation from $\mathrm{WHO}$ recommended exposure standard of ionizing radiation in Buruburu.

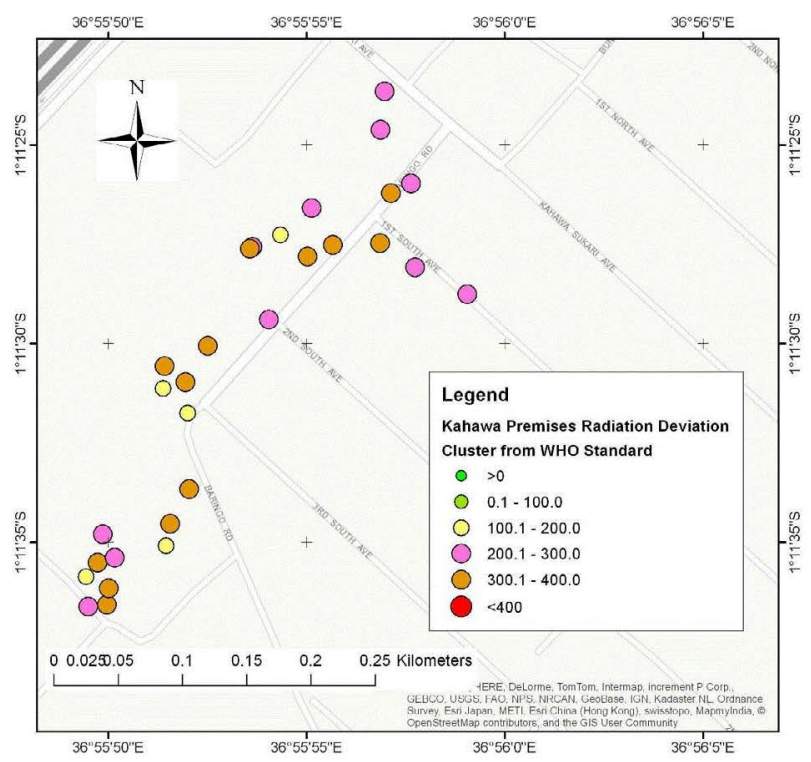

Figure 10: Percentage annual deviation from WHO recommended exposure standard of ionizing radiation in Kahawa.

Brazil [14]. According to a study in 2013 classified radiation areas as low (less than $5 \mathrm{mSv})$, medium (5-10 mSv), high (20-50 mSv) and very high (greater than $50 \mathrm{mSv}$ ) [15]. In China, Yangjiang is a high natural background radiation area. The primary source of this radiation is high levels of $U 232$ and Th 238 [16]. Its annual effective dose rate equivalent is $4.27 \mathrm{mSv}$ [17]. A health survey conducted showed that the children in the high background radiation areas had chromosomal translocation at low frequencies. Another study in 2011 showed that there was a positive correlation between dicentrics and ring chromosomes (Dic+Rc) and age in high background radiation areas. The frequency of Dic+Rc linearly increased over lifetime due to chronic low dose exposure. A biological and epidemiological study in Ramsar showed increased chromosomal aberrations [18]. In addition, a study in 1993 showed a significant positive response in cytogenetic results of the study group compared with the control group particularly in the house with the highest level of exposure [19]. A more recent study by Taeb in 2014 investigated the alterations in 8 tumor markers in blood samples from residents of Ramsar. From the study, there was a significant difference correlation between chronic exposure and concentration of 3 of the 8 investigated tumor markers. Cytogenetic studies have revealed adaptive response and chromosomal aberrations in residents of Ramsar [20]. Adaptive response is a phenomenon whereby the body is resistant to high radiation doses. This study reported that there was an increased level if IgE and high incidence of chromosome aberrations in high background radiation areas (HBRA) [20,21]. Another research showed a correlation between exposure to high levels of background natural radiation and incidence of cancer mortality. The high mortality rate was seen in females from high background radiation areas than normal background radiation areas [22]. This was attributed to the high levels of indoor radon dose because most female residents remained indoors [23] and there was positive relationship between high indoor radon levels and elevated lung cancer risk. Biological damage occurs due to chemical changes caused by ionization at the cellular level. Charged particles like alpha particles can ionize the human DNA leading to genetic damage like chromosomal abberations, thereby inducing carcinogenesis. Many human malignant tumors exhibit abnormal chromosomal segregation at cell division. It is believed that these anomalies play a role in tumorigenesis by increasing the rate of chromosome mutations, including deletion and

amplification of genes involved in cellular proliferation and/ or survival [24]. In vitro experiments have also shown that mitotic instability may be a mechanism for developing resistance to cytotoxic drugs. Abnormal mitotic mechanisms may result in numerical or structural aberrations in the daughter cells. Numerical aberrations can be caused either by the loss of chromosomes at metaphase/anaphase or by multipolar divisions associated with abnormal number or structure of centrosomes. Structural rearrangements have been associated with chromosomal breakage-fusion-bridge (BFB) cycles that can be initiated by telomeric dysfunction, giving rise to unstable dicentric or ring chromosomes. In most tumors exhibiting chromosomal instability, including high-grade malignant pancreatic, ovarian, and head and neck carcinomas. All malignant tumor types have been shown to contain chromosomal aberrations. The pattern of abnormalities varies greatly between malignancies, ranging from simple balanced rearrangements to complex abnormalities affecting both chromosome structure and number [25]. In hematological neoplasms, certain abnormalities are often strongly associated with specific

diagnostic entities. Typically, these changes are reciprocal translocations such as the $t(9 ; 22)$ in chronic myelogenous leukaemia [25]. Similar genetic abnormalities are seen in some solid tumors, for example the $(11 ; 22)$ translocation in Ewing sarcomas and the inversion of proximal $10 \mathrm{q}$ in papillary thyroid carcinomas [26]. Studies on the Chernobyl accident show that workers had severe radiation effects. Doses to the thyroid received in the first few months after the accident were particularly high in those who were children and adolescents who drank milk with high levels of radioactive iodine. By 2005, more than 6,000 thyroid cancer cases had been diagnosed in this group, and it is most likely that a large fraction of these thyroid cancers is attributable to radioiodine intake. There is also increased incidence of leukemia and opacities of the eye lens might be caused by relatively low radiation doses [27]. Radiation acts primarily by inducing DNA damage in somatic cells. A range of DNA lesions will form through direct energy deposition in DNA or through the indirect action of free radicals;however, double-strand breaks and complex lesions in DNA are likely to be most important in causing mutations. Systems exist to repair damage in nuclear DNA. However no repair is completely error free, although some repair systems tend to be more error-prone than others. Consequently, even the lowest doses of radiation may induce 
Page 6 of 7

\begin{tabular}{|c|c|c|c|c|c|c|c|c|}
\hline $\begin{array}{c}\text { Deviation cluster } \\
(\%)\end{array}$ & Mlolongo & CBD & Kasarani & Eastleigh & Ruaka & Kinoo & Buruburu & Kahawa \\
\hline & $(\%)$ & $(\%)$ & (\%) & (\%) & $(\%)$ & $(\%)$ & $(\%)$ & $(\%)$ \\
\hline $0<$ & 0 & 0 & 0 & 0 & 0 & 0 & 0 & 0 \\
\hline $1-100$ & 2 & 6 & 2 & 0 & 0 & 0 & 2 & 0 \\
\hline $101-200$ & 58 & 67 & 30 & 15 & 7 & 7 & 14 & 19 \\
\hline $201-300$ & 25 & 21 & 48 & 34 & 55 & 45 & 47 & 36 \\
\hline $301-400$ & 15 & 6 & 16 & 38 & 32 & 31 & 32 & 45 \\
\hline$>400$ & 0 & 0 & 4 & 13 & 6 & 17 & 5 & 0 \\
\hline
\end{tabular}

Table 1: Number of premises (\%) and percentage annual deviation from WHO recommended exposure standard of ionizing radiation in selected estates around Nairobi County.

\begin{tabular}{|c|c|}
\hline Deviation cluster (\%) & Number of units (\%) \\
\hline $0<$ & 0 \\
\hline $1-100$ & 2 \\
\hline $101-200$ & 33 \\
\hline $201-300$ & 36 \\
\hline $301-400$ & 24 \\
\hline$>400$ & 5 \\
\hline
\end{tabular}

Table 2: Percentage annual deviation from WHO recommended standard of ionizing radiation in Nairobi County and its environs.

\begin{tabular}{|c|c|c|}
\hline Estates & $\begin{array}{l}\text { Annual Indoor } \\
\text { Average (mSv) }\end{array}$ & $\begin{array}{l}\text { Percentage deviation from WHO } \\
\text { recommended standard }\end{array}$ \\
\hline Buruburu & $3.752 \pm 0.096 \mathrm{ab}$ & $275.20 \%$ \\
\hline CBD & $2.763 \pm 0.060 d$ & $176.30 \%$ \\
\hline Eastleigh & $4.070 \pm 0.118 a$ & $307 \%$ \\
\hline Kahawa & $3.713 \pm 0.129 a b$ & $271.30 \%$ \\
\hline Kasarani & $3.407 \pm 0.105 b c$ & $240.70 \%$ \\
\hline Kinoo & $4.032 \pm 0.146 a$ & $303.20 \%$ \\
\hline Mlolongo & $3.105 \pm 0.121 \mathrm{~cd}$ & $210.50 \%$ \\
\hline Ruaka & $3.976 \pm 0.121 a$ & $297.60 \%$ \\
\hline \multicolumn{3}{|c|}{$\begin{array}{l}\text { Values are expressed as Mean } \pm \text { SEM. Values followed by the same superscript } \\
\text { are not significantly different ( } p \leq 0.05 \text {; One way ANOVA followed by Tukey's } \\
\text { post hoc test) }\end{array}$} \\
\hline
\end{tabular}

Table 3: Annual exposure to ionizing radiation in premises around Nairobi County and its environs.

DNA damage that may be converted into DNA sequence mutations. Cancer development originates from single cells that have sustained mutations through DNA damage. Such cells gain growth advantages and progress to a proliferative and ultimately malignant tumor. Radiation can also induce apoptosis and influence cell-cycle checkpoints, which together can affect the outcome of a radiation exposure. Most evidence suggests that DNA deletions are the major contributors to the mutations driving radiation carcinogenesis. In somatic carcinogenesis, radiationinduced initiating events are but one of many steps required for tumor formation. By contrast, direct induction of mutations in the germ line, where compatible with viability, will directly contribute to the burden of heritable mutations and possible heritable disease [27]. Some of

the mitigation measures that have been used to reduce exposure to ionizing radiation include building of walls with material that absorbs radiation, such as $230 \mathrm{~mm}$ baked solid clay bricks, lead sheet of $2 \mathrm{~mm}$ be sandwiched between other bricks, use of lead sheets between building blocks to prevent radiation passing unhindered through the open areas and barium plastering of at least $6 \mathrm{~mm}$ of thickness to cover the walls. Barium has a relatively high atomic number (56) there by absorbing some radiation.

\section{Conclusion}

None of the premises sampled had their annual indoor ionizing radiation below the safe levels. This means that majority of the occupants of the premises are exposed to relatively to high doses of radiation. This may not have an immediate health impact but in the long term, cumulative dose can become hazardous. From this study, it is recommended that regular and periodic monitoring of the background ionizing radiation level should be carried out in various buildings to assess the health risk of the general public and also ensure that areas of potential risks are identified early enough and the risk mitigated. Additionally, public awareness on the risks and dangers of long term of exposure to background ionizing radiations to the general public should be conducted. Consequently, the results for the study can be used as a guide in formulation of the national building code to include radiation surveillance during construction.

\section{References}

1. Jwanbot DI (2011) Measurement of radioactivity levels in soil and food samples in mining areas on the Jos-Plateau, Nigeria. Unpublished PhD Thesis University of Jos 139

2. Ike EE (2003) Introductory University Physics, First Edition, Published by ENIC Education Consultants and Publishers Abia State.

3. Hayumbu P, Zaman MB, Lababa NHC, Munsanje SS, Meleya D (1995) Natura Radioactivity in Zambian building materials collected from Lusaka. Journal of radio analytical Nuclear Chemistry Letter 11, 299.

4. Chad-Umoren YE, Adekanmbi M, Harry SO (2007) Evaluation of Indoor Background lonizing Radiation Profile of a Physics Laboratory. Facta Universitatis Series: Working and Living Environmental Protection 3: 1-7.

5. 5. Solomon AO, Ike EE, Ashano EC, Jwanbot DI (2000). National Background Radiation Characteristics of basalt on the Jos Plateau and the Radiological implication of the use of the Rock for house construction. African Journal of Natural Sciences 5.

6. Wentz CA (1998) Safety, Health and Environmental Protection. Mc Gram Hill, Boston, USA: 206-219.

7. Oresegun MO, Babalola IA (1990) Occupational Radiation Exposure Associated with Milling of Th-U rich Sn in Nigeria. Health Phys 58: 213-215.

8. Orsini S, Campoleoni M, Rotta M, Terrana T (1991) Sources of lonizing Radiation in Dwellings. Med. Lav 82: 347-357. 
Citation: Ogola PE, Arika WM, Nyamai DW, Osano KO, Rachuonyo HO, et al. (2016) Determination of Background lonizing Radiations in Selected Buildings in Nairobi County, Kenya. J Nucl Med Radiat Ther 7: 289. doi:10.4172/2155-9619.1000289

9. Mitelman F (1990) Patterns of chromosome variation in neoplasia. In Chromosomal Aberrations (pp. 86-100). Springer Berlin Heidelberg 1-2.

10. Masok FB, Dawam RR, Mangset EW (2015) Assessment of Indoor and Outdoor Background Radiation Levels in Plateau State University Bokkos Jos, Nigeria. Journal of Environment and Earth Science 5: 1-4

11. Chad-Umoren YE, Adekanmbi M, Harry SO (2006) Evaluation of Indoor Background lonizing Radiation Profile of a Physics Laboratory. Facta Universitatis series Working and Living Environmental Protection 3: 1-8

12. Okoye PC, Avwiri GO (2013) Evaluation of background ionising radiation levels of Braithwaite Memorial Specialist Hospital Port Harcourt, Rivers State. Am. J. Sci. Ind. Res 4: 359-365.

13. Ghiassi-Nejad M, Mortazavi SMJ, Cameron JR, Niroomand-Rad A, Karam PA (2002) Very high background radiation areas of Ramsar, Iran: preliminary biological studies. Health Physics 82: 87-93.

14. Ibeanu IGE (2004) Comparison of background dose rate measurements in Nigeria with other countries. Zuma Journal of Pure and Applied Sciences 6 : 19-24.

15. Sohrabi M (2013) Recent radiological studies of high level natural radiation areas of Ramsar. Proceeding of International Conference on High Levels of Natural Radiation, Ramsar, Iran. Vienna: IAEA.

16. Yuan YL (1997) Recent advances in dosimetry investigation in the high background radiation area in Yangjiang, China. High Levels of Natural Radiation: Radiation Dose and Health Effects, Eds. L.X. Wei, T. Sugahara and Z.-F. Tao (1997) : 223-233.

17. Kamara S, Dunn DI (2014) Monitoring of Occupationally exposed workers in Industrial Radiography due to External Radiation. The Fourth Regional African Congress of International Radiation Protection Association.
18. Zakeri F, Rajabpour MR, Haeri SA, Kanda R, Hayata l et al. (2011) Chromosome aberrations in peripheral blood lymphocytes of individuals living in high background radiation areas of Ramsar, Iran. Radiation and environmental biophysics 50: 571-578.

19. Fazeli TZ (1993) Cytogenetic studies of inhabitants of a high level natural radiation area of Ramsar. In: Proceeding of International Conference on High Levels of Natural Radiation, Ramsar, Iran. Vienna: IAEA 459-464.

20. Taeb JM, Klein A, Brahmer JR, Xu H, Pan X, et al. (2014) Association of PD-1, PD-1 ligands, and other features of the tumor immune microenvironment with response to anti-PD-1 therapy. Clinical Cancer Research 20: 5064-5074.

21. Xu Y, Tao X, Shen B, Horng T, Medzhitov R, et al. (2000) Structural basis forsignal transduction by the Toll/interleukin-1 receptor domains. Nature 408 111-115

22. Darby S, Hill D, Auvinen A, Barros-Dios JM, Baysson H, et al. (2005) Radon in homes and risk of lung cancer: collaborative analysis of individual data from 13 European casecontrol studies. Bmj $330: 223$.

23. Pandis N, Jin Y, Gorunova L, Petersson C, Bardi G, et al. (1995) Chromosome analysis of 97 primary breast carcinomas: identification of eight karyotypic subgroups. Genes,chromosomes and cancer 12: 173-185.

24. Zou W (2005) Immunosuppressive networks in the tumour environment and their therapeutic relevance. Nature Reviews Cancer 5: 263-274.

25. Djebali S, Davis CA, Merkel A, Dobin A, Lassmann T, et al. (2012) Landscape of transcription in human cells. Nature 489: 101-108.

26. Chernobyl Report Forum (2008) Radiation carcinogenesis: lessons from Chernobyl. Oncogene 27: 9-18

27. Santoro M, Thomas GA, Vecchio G, Williams GH, Fusco A, et al. (2000) Gene rearrangement and Chernobyl related thyroid cancers. British journal of cancer 82: 315 